\title{
Local and remote response of ozone to Arctic stratospheric circulation extremes
}

\author{
Hao-Jhe Hong ${ }^{1,2}$ and Thomas Reichler ${ }^{1}$ \\ ${ }^{1}$ Department of Atmospheric Sciences, University of Utah, Salt Lake City, UT 84112, USA \\ ${ }^{2}$ Research Center for Environmental Changes, Academia Sinica, Taipei City, 11529, Taiwan
}

Correspondence: Hao-Jhe Hong (haojhe.hong@utah.edu)

Received: 29 July 2020 - Discussion started: 17 August 2020

Revised: 7 December 2020 - Accepted: 13 December 2020 - Published: 28 January 2021

\begin{abstract}
Intense natural circulation variability associated with stratospheric sudden warmings, vortex intensifications, and final warmings is a typical feature of the winter Arctic stratosphere. The attendant changes in transport, mixing, and temperature create pronounced perturbations in stratospheric ozone. Understanding these perturbations is important because of their potential feedbacks with the circulation and because ozone is a key trace gas of the stratosphere. Here, we use Modern-Era Retrospective analysis for Research and Applications, version 2 (MERRA-2), reanalysis to contrast the typical spatiotemporal structure of ozone during sudden warming and vortex intensification events. We examine the changes of ozone in both the Arctic and the tropics, document the underlying dynamical mechanisms for the observed changes, and analyze the entire life cycle of the stratospheric events - from the event onset in midwinter to the final warming in early spring. Over the Arctic and during sudden warmings, ozone undergoes a rapid and long-lasting increase of up to $\sim 50 \mathrm{DU}$, which only gradually decays to climatology before the final warming. In contrast, vortex intensifications are passive events, associated with gradual decreases in Arctic ozone that reach $\sim 40 \mathrm{DU}$ during late winter and decay thereafter. The persistent loss in Arctic ozone during vortex intensifications is dramatically compensated by sudden warming-like increases after the final warming. In the tropics, the changes in ozone from Arctic circulation events are obscured by the influences from the quasi-biennial oscillation. After controlling for this effect, small but coherent reductions in tropical ozone can be seen during the onset of sudden warmings $(\sim 2.5 \mathrm{DU})$ and also during the final warmings that follow vortex intensifications $(\sim 2 \mathrm{DU})$. Our results demonstrate that Arctic circulation extremes have
\end{abstract}

significant local and remote influences on the distribution of stratospheric ozone.

\section{Introduction}

The wintertime Arctic stratosphere is characterized by a number of dynamical, chemical, and physical processes that are coupled to each other in intriguing ways. For example, extreme stratospheric circulation events from the interaction (or lack thereof) of upward-propagating, planetary-scale Rossby waves with the polar vortex create a pronounced dynamical variability in the Arctic. A large concentration of ozone is another important characteristic of the Arctic stratosphere. Ozone is an effective absorber of solar radiation and an important player in the coupling between the chemistry, radiation, and dynamics. The diabatic heating from ozone impacts the temperatures and the winds, and the induced dynamical transport and photochemical reactions again impact the ozone. The feedback between ozone and the circulation may sustain the circulation anomalies and modify the stratospheric sensitivity to external forcings (Hartmann et al., 2000). Ozone is also important for the protection of life on Earth by absorbing harmful ultraviolet radiation. Taken together, ozone is a crucial stratospheric constituent, and understanding the factors that influence its distribution is a critical goal of climate research.

Ozone in the Arctic lower stratosphere is mostly controlled by transport. The transport intensifies in the winter hemisphere (Randel, 1993; Randel et al., 2002), creating a springtime total ozone maximum at high latitudes. The seasonality of the transport is associated with an intensification of the 
upward-propagating Rossby waves in winter. At times, the bursts of waves and their interaction with the polar vortex are strong enough to create so-called major stratospheric sudden warming events (SSWs; McIntyre, 1982; Limpasuvan et al., 2004; Polvani and Waugh, 2004), arguably the most important form of stratospheric circulation events. In the process, polar temperatures increase rapidly, reverse the climatological Equator-to-pole temperature gradient, and cause the normal westerly flow of the vortex to become easterly (Scherhag, 1952). SSWs occur in about 2 of every 3 years (Butler et al., 2017), most often in January or February (Horan and Reichler, 2017).

Past studies pointed out the close coupling between the stratospheric dynamics and Arctic ozone (e.g., Leovy et al., 1985; Ma et al., 2004), with a positive correlation between polar ozone tendencies and the stratospheric wave driving (Randel et al., 2002). The coupling leads to enhanced poleward ozone transport during SSWs and creates persistent ozone anomalies in the lowermost stratosphere (Butler et al., 2017; Hocke et al., 2015). De la Cámara et al. (2018b) showed that the initial increase in ozone after SSWs is mainly driven by isentropic eddy fluxes associated with the enhanced wave driving, while the subsequent recovery of ozone can be attributed to the competing effects between cross-isentropic advection and irreversible isentropic mixing.

It is perhaps less well known that the influence of SSWs on ozone can also influence the tropics. Randel (1993) demonstrated how vertical transport from the 1979-1980 SSW affected tropical ozone in the lower stratosphere and how the changes in ozone were correlated with temperatures in the upper stratosphere. The SSW-related influences on the tropics also imprint on the variability in temperature and water vapor there (Gómez-Escolar et al., 2014; Tao et al., 2015). However, the SSW effect on tropical ozone is superimposed on the effects from the quasi-biennial oscillation (QBO), which are downward-propagating westerly and easterly zonal wind anomalies with a cycle of $\sim 28$ months (Baldwin et al., 2001; Coy et al., 2016; Randel and Wu, 1996) that also influence ozone.

The winter Arctic stratosphere not only witnesses occasional SSWs. A sustained lack of stratospheric wave driving can create the opposite events to SSWs, i.e., so-called vortex intensification events (VIs). VIs are characterized by an unusually strong and cold polar vortex (Limpasuvan et al., 2005) and reduced transport of ozone into the pole region (Isaksen et al., 2012). The extreme cold during VIs favors halogen-induced chemical ozone depletion, which, in combination with the weakened transport, leads to record-low levels of ozone that can be comparable in magnitude to the southern hemispheric counterpart (Isaksen et al., 2012; Manney et al., 2011). A good example is the most recent winter 2019-2020, which experienced an exceptionally strong, cold, and persistent Arctic stratospheric polar vortex, and which led to record-breaking Arctic ozone depletion.
Another important class of stratospheric circulation events is stratospheric final warming events (FWs). FWs occur every year at the end of winter, representing the final breakdown of the polar vortex due to the seasonal increase in solar heating. FWs are often triggered by pulses of increased wave activity and can be considered as SSWs that conclude the winter season (Black and McDaniel, 2007). There also exists an interesting temporal relationship between FWs, SSWs, and VIs, namely that FWs that are preceded by SSWs in the same winter tend to occur significantly later than the mean FW date ( mid-April; Horan and Reichler, 2017), and FWs that are preceded by non-SSW winters (i.e., neutral winter and VIs) tend to be relatively early (Hu et al., 2014). This can be explained from the delayed relationship between vortex strength and wave driving. An SSW, for example, is usually followed by reduced wave activity and, hence, a stronger vortex, which then breaks down later in spring. The changes in FW timing also impact the levels of Arctic ozone. Manney and Lawrence (2016) showed that the chemical ozone loss from the 2016 VI was disrupted by an early FW at the beginning of March and suggested that FWs may have comparable effects on Arctic ozone as SSWs.

While the aforementioned studies have started to investigate the response of ozone in the Arctic to SSWs, the response of ozone in the tropics, and also to VI and FW events, has received little attention so far. This study intends to fill this gap and refine the existing knowledge about the spatiotemporal relationship between ozone and a range of Arctic stratospheric circulation events using a modern, observationbased perspective. We achieve this by taking a comparative approach that contrasts the often opposing ozone behavior between SSWs and VIs and between the Arctic and the tropics. Time is another distinctive aspect of this study, as we cover the entire life cycle of the stratospheric circulation events from the event onset in the middle of winter to the date of the FW at the end of winter. We also clarify the role of the associated dynamical and photochemical processes in changing ozone. Overall, our goal is to provide an up-to-date, observation-based view of the global natural dynamic-driven variability in stratospheric ozone. This is not only of interest in its own right but also provides an observational baseline for ozone behavior during stratospheric circulation events that can be used for the validation of coupled chemistryclimate models.

This paper is structured as follows. In Sect. 2, we describe the data and methods used in this study. In Sect. 3, we demonstrate the ozone response in the Arctic, while in Sect. 4 we continue our discussion of the tropics. A summary and conclusion are provided in Sect. 5 . 


\section{Data and methods}

\subsection{Modern-Era Retrospective analysis for Research and Applications, version 2 (MERRA-2), data}

We use 1980-2018 daily fields from the MERRA-2 reanalysis (Bosilovich et al., 2015) at a horizontal resolution of $1.5^{\circ}$ and 37 levels ranging from 1000 to $0.1 \mathrm{hPa}$. MERRA-2 also provides ozone, which is based on retrievals from the solar backscatter ultraviolet (SBUV; January 1980-September 2004) and Aura Ozone Monitoring Instrument/Microwave Limb Sounder (OMI/MLS; October 2004-present) instruments (Davis et al., 2017) and on a simple ozone scheme (Rienecker et al., 2008). MERRA2 has been shown to perform well for ozone through much of the stratosphere (Davis et al., 2017; Wargan et al., 2017). Most of our calculations are based on zonal mean quantities. We compute daily climatologies from MERRA-2 by averaging each day of the year over the entire record and smoothing over the seasonal cycle using $10 \mathrm{~d}$ running means. Daily anomalies are obtained by subtracting the climatologies from the daily data.

\subsection{Event definition}

In defining SSWs and FWs, we follow the widely used prescription by Charlton and Polvani (2007). An SSW is detected when the zonal mean zonal wind at $10 \mathrm{hPa}$ and $60^{\circ} \mathrm{N}$ (U1060) switches from westerly to easterly (the central date of the event) during November-March and returns to the westerly condition for at least 10 consecutive days before 30 April. If the return to the westerly condition is not fulfilled, the event is considered as the FW of the year. A total of two or more SSWs in the same winter must be separated by consecutive westerlies for at least $20 \mathrm{~d}$. Since we are interested in the evolution of ozone over the life cycle of SSWs from the middle to the end of the winter, we only consider midwinter SSWs during January or February. We also discard midwinter SSW events that are followed by another, potentially disturbing, SSW, leading to the exclusion of only one event.

Our definition of midwinter VIs is also based on U1060, but we first low-pass filter the data, using $20 \mathrm{~d}$ running means. A midwinter VI occurs when the smoothed daily U1060 anomaly during January or February exceeds 1 standard deviation $\left(16 \mathrm{~m} \mathrm{~s}^{-1}\right)$, marking the central date of the VI. Like SSWs, two VIs in the same winter must be separated by at least $20 \mathrm{~d}$. We only consider VIs that are not followed by another VI or SSW.

As shown in Table 1, our definitions lead to $15 \mathrm{SSWs}$ and 8 VIs. For SSWs, the mean central date and the associated FW date are 3 February and 26 April, respectively, leading to a mean length of time of $83 \mathrm{~d}$ (ranging from 54 to 117). VIs have a mean central date on 23 January and an associated FW date on 2 April. This translates into a mean length of time
Table 1. Central dates $t_{0}$ of SSWs and VIs. Numbers in parentheses indicate length of time (in days) between the central date and the following $\mathrm{FW}$, i.e., $t_{\mathrm{FW}}-t_{0}$.

\begin{tabular}{lll}
\hline No. & SSW central date & VI central date \\
\hline 1 & 24 Feb 1984 (61) & 3 Jan 1983 (88) \\
2 & 1 Jan 1985(82) & 19 Jan 1993(83) \\
3 & 23 Jan 1987(99) & 17 Feb 1994 (44) \\
4 & 21 Feb 1989(54) & 29 Jan 1996(72) \\
5 & 26 Feb 1999 (66) & 29 Jan 1997(91) \\
6 & 11 Feb 2001 (88) & 9 Jan 2005(62) \\
7 & 17 Feb 2002 (77) & 7 Feb 2011 (57) \\
8 & 18 Jan 2003(86) & 6 Jan 2016(59) \\
9 & 5 Jan 2004 (116) & \\
10 & 21 Jan 2006(106) & \\
11 & 24 Feb 2007 (54) & \\
12 & 22 Feb 2008 (69) & \\
13 & 24 Jan 2009(106) & \\
14 & 6 Jan 2013 (117) & \\
15 & 12 Feb 2018 (63) & \\
\hline Mean & 3 Feb (83) & 23 Jan (70) \\
\hline
\end{tabular}

of $70 \mathrm{~d}$ (ranging from 44 to 91). Note that SSWs are longer in the length of time than VIs, consistent with the findings by Hu et al. (2014) that SSW winters are associated with FW dates that are, on average, late compared to the climatological mean FW date.

We use a $180 \mathrm{~d}$ running mean window to smooth the zonal mean equatorial $\left( \pm 5^{\circ}\right)$ zonal wind at $30 \mathrm{hPa}$ (UEQ30) and determine the phase of the QBO. A QBO cycle is defined as the period between two consecutive positive UEQ30 maxima, and the UEQ30 minimum in between is considered as the midpoint of the cycle. We exclude the anomalous QBO cycle of 2015-2016 (Newman et al., 2016) from our analysis and obtain 16 QBO cycles over the 1980-2018 period.

\subsection{Ozone and dynamics diagnostics}

The changes in zonal mean ozone $(\bar{\chi})$ are investigated using the transformed Eulerian mean (TEM) approach. Following Andrews et al. (1987), the TEM tracer transport equation in pressure coordinates, in the following:

$\overline{\chi_{\mathrm{t}}}=-\bar{v}^{*} \bar{\chi}_{y}-\bar{\omega}^{*} \bar{\chi}_{\mathrm{p}}-\rho_{0}^{-1} \nabla \cdot \boldsymbol{M}+\bar{S}$,

is used to decompose the ozone tendency $\left(\overline{\chi_{\mathrm{t}}}\right)$ into two advection terms associated with the residual mean circulation, one term due to eddy flux convergence $\left(-\rho_{0}^{-1} \nabla \cdot \boldsymbol{M}\right)$, and a source term $(\bar{S})$ that represents the effects of chemistry on ozone. Here, $\bar{v}^{*}$ and $\bar{\omega}^{*}$ are the components of the residual mean circulation, $\rho_{0}$ is the basic state density, and $\boldsymbol{M}$ is an eddy flux vector given by the following: 


$$
\begin{aligned}
\boldsymbol{M}= & {\left[\rho_{0}\left(\overline{v^{\prime} \chi^{\prime}}-\overline{v^{\prime} \theta^{\prime}} \bar{\chi}_{\mathrm{p}} / \bar{\theta}_{\mathrm{p}}\right),\right.} \\
& \left.\rho_{0}\left(\overline{\bar{\omega}^{\prime} \chi^{\prime}}+\overline{v^{\prime} \theta^{\prime}} \bar{\chi}_{y} / \bar{\theta}_{\mathrm{p}}\right)\right],
\end{aligned}
$$

where overbars denote zonal means, primes are deviations from zonal means, and the other terms are standard notation. The eddy flux convergence contains effects that are not explained by the advection of zonal mean ozone by the zonal mean circulation. The convergence is associated with the transport of zonal disturbances in ozone by zonal disturbances in meridional or vertical velocity. In the stratosphere, these disturbances (or eddies) are primarily due to upward-propagating planetary waves. The convergence term indicates that covariance between eddy velocities and ozone can transport ozone, and that where this eddy ozone flux converges, a zonal mean ozone tendency can be induced. For example, a northward ozone flux is created if the signs of the meridional velocity and the ozone perturbations tend to be the same, and if this flux decreases in the northward direction (converges), it would create a positive ozone tendency in the zonal mean. Our result (not shown) suggests that the meridional component of the eddy flux convergence (the first term of the $\boldsymbol{M}$ vector in Eq. 1) dominates the vertical component over most of the stratosphere.

The ozone tendency $\overline{\chi_{t}}$ is calculated by taking forward differences in the time of daily ozone, and the chemical source term $\bar{S}$ is the residual between $\overline{\chi_{\mathrm{t}}}$ and the sum of the three dynamical terms in Eq. (1). We note that the resulting $\bar{S}$ does not exclusively reflect the chemical production or destruction of ozone because of the unavoidable errors of MERRA-2 and computational uncertainties. For example, in the absence of observations, the MERRA-2 ozone is calculated from a simple parameterization (Rienecker et al., 2008), which can result in considerable errors. Because of this uncertainty, and also because of the focus of this study on the dynamical impacts, we do not show the $\bar{S}$ term.

We use $F_{\mathrm{p}}$, the vertical component of the quasigeostrophic Eliassen-Palm (EP) flux (Eliassen and Palm, 1961), to diagnose the upward-propagating Rossby wave activity. Following Andrews et al. (1987), $F_{\mathrm{p}}$ is given by the following:

$$
F_{\mathrm{p}}=-\operatorname{acos} \phi f \frac{\overline{v^{\prime} \theta^{\prime}}}{\theta_{\mathrm{p}}}
$$

where all symbols are standard notation. In our analysis, we reverse the sign of $F_{\mathrm{p}}$ so that positive $F_{\mathrm{p}}$ corresponds to the upward propagation. We focus on $F_{\mathrm{p}}$ at $100 \mathrm{hPa}$, averaged over $40-80^{\circ} \mathrm{N}$, and refer to this quantity as the stratospheric wave driving.

\subsection{Event compositing}

Traditional composites take the averages of various events centered on specific dates (e.g., Butler et al., 2017). However, in the present study, we are interested in the behavior of ozone during the entire life cycle of stratospheric circulation events, beginning in December before the onset and ending with the FW at the end of winter. Our interest in this rather long period is rooted in the fact that the events and their ozone anomalies can be quite persistent, and that the FW represents yet another perturbation to the preexisting ozone fields. Since each event and FW occur at different dates, it is useful to measure the time between the central date of an event and its associated FW. This is denoted as the length of time. Since the length of time differs from event to event, we somewhat modify the traditional compositing technique. Our approach is based on the mean central date of all selected SSWs (or VIs; $\overline{t_{0}}$ ) and the mean date of their associated FWs $\left(\overline{t_{\mathrm{FW}}}\right)$. We then use linear interpolation in time to align the dates of the individual events $\left(t_{0}, t_{\mathrm{FW}}\right)$ with the composite mean dates $\left(\overline{t_{0}}, \overline{t_{\mathrm{FW}}}\right)$. Mathematically, this can be written as follows:

$\bar{t}=\overline{t_{0}}+\left(t-t_{0}\right) \cdot \frac{\overline{t_{\mathrm{FW}}}-\overline{t_{0}}}{t_{\mathrm{FW}}-t_{0}}$,

where $\bar{t}$ denotes the time of the composite, and $t$ is the time of individual events. The interpolation can be interpreted as a stretching or squishing of the time axis so that all data during $t_{0}\left(t_{\mathrm{FW}}\right)$ are aligned with $\overline{t_{0}}\left(\overline{t_{\mathrm{FW}}}\right)$. The mean length of time $\left(\overline{t_{\mathrm{FW}}}-\overline{t_{0}}\right)$ of SSWs (VIs) is then $83(70) \mathrm{d}$. The length of time of the individual events $\left(t_{\mathrm{FW}}-t_{0}\right)$ is shown in Table 1 . We use this technique to create composites of various quantities at daily intervals. A two-tailed Student's $t$ test at the $95 \%$ confidence level is used to test the statistical significance of the composite mean anomalies against the null hypothesis of zero anomalies.

\section{Arctic ozone}

\subsection{Arctic circulation changes}

We begin our discussion of how Arctic ozone evolves during SSWs and VIs by presenting some key dynamical quantities, which will then guide the interpretation of our subsequent results. Figure 1 shows the evolution of composite anomalies in the stratospheric wave driving (Fig. 1a, b), the vertical component of the residual circulation (Fig. 1c, d), and temperature (Fig. 1e, f) over the life cycle of SSWs (Fig. 1a, c, e) and VIs (Fig. 1b, d, f).

SSWs (Fig. 1a, c, e) are typically preceded by enhanced stratospheric wave driving, starting at a negative lag of $\sim 15 \mathrm{~d}$ (Fig. 1a). This leads to the breakdown of the polar vortex and marks the onset of the SSW (Limpasuvan et al., 2004). After the onset, the wave driving decreases rapidly and becomes 

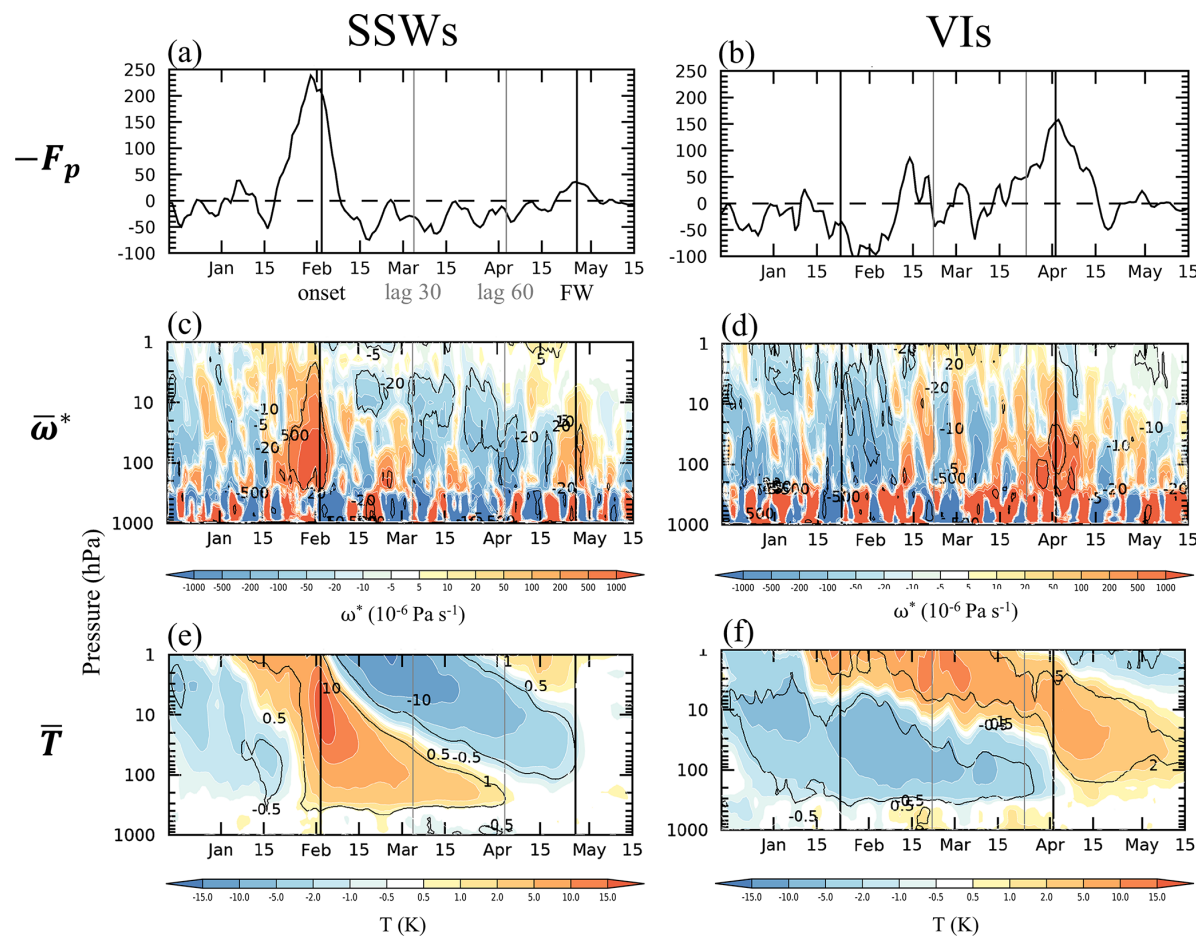

Figure 1. SSW (a, c, e) and VI (b, d, f) composites over the Arctic. Shown are (a-b) the time series of $10 \mathrm{~d}$ smoothed vertical EP flux $\left(10^{4} \mathrm{~kg} \mathrm{~m} \mathrm{~s}^{4}\right)$ averaged over $40-80^{\circ} \mathrm{N}$ at $100 \mathrm{hPa}$, and time-height cross sections for (c-d) the vertical component of the residual circulation $\left(10^{-6} \mathrm{~Pa} \mathrm{~s}^{-1} ; 65-85^{\circ} \mathrm{N}\right)$ and $(\mathbf{e}-\mathbf{f})$ temperature $\left(\mathrm{K} ; 65-90^{\circ} \mathrm{N}\right)$. Contours represent the statistical significance at the $95 \%$ level.

negative, contributing to the over-recovery of the vortex in the upper stratosphere, reminiscent of so-called polar-night jet events (de la Cámara et al., 2018a; Hitchcock and Shepherd, 2013; Kuroda and Kodera, 2001). As pointed out by Plumb and Eluszkiewicz (1999) and demonstrated by Fig. 1c, this cyclic nature of the wave driving imprints on the residual circulation of the entire stratosphere. Figure 1c shows that the vertical component of the residual circulation $\left(\bar{\omega}^{*}\right)$ over the Arctic varies consistently with the wave driving, with enhanced downwelling during onset (reddish colors), followed by a long period of enhanced upwelling (bluish colors). The cycle ends at the end of winter, with somewhat enhanced wave driving and subsequent downwelling during the FW. Arctic temperatures (Fig. 1e) are characterized by cooling before the SSW, strong warming in the middle to lower stratosphere during and after the onset, and cooling after the onset in the upper to the middle stratosphere. The patterns of warming and cooling following the onset give the impression of a downward propagation. However, the cooling in the upper stratosphere is associated with the aforementioned suppressed wave driving and subsequent radiative cooling (Hitchcock and Shepherd, 2013; Limpasuvan et al., 2004), and the persistence of the warming in the lower stratosphere is related to the long radiative timescale in this part of the stratosphere.

VIs (Fig. 1b, d, f) are, in many respects, opposite to SSWs. As explained in Limpasuvan et al. (2005), VIs evolve rel- atively slowly and result from the sustained lack of stratospheric wave driving, leading to the gradual strengthening and cooling of the vortex. As shown by Fig. 1b, the wave driving is anomalously small, starting several weeks before onset and minimizing at about 1 week after onset. This is different from SSWs, as the wave driving during SSWs changes much more abruptly during onset. Long after the onset of VIs, the wave driving increases again, first more intermittently and then more systematically during the FW. We note that the magnitude of the wave driving associated with the FW is quite large and comparable to that of SSWs during onset. This may be attributable to the sustained suppression of wave driving during VI onset, contributing to the enhanced release of wave activity after the event and a relatively early FW. Also, the relatively strong polar vortex after VIs (not shown) is conducive to upward-propagating wave activity into the stratosphere.

As for SSWs, changes in the Arctic $\bar{\omega}^{*}$ during VIs (Fig. 1d) agree well with the evolution of wave driving. The upwelling maximizes 1 week after VI onset, followed by a period of intermittent downwelling before the FW (see also Limpasuvan et al., 2005). VIs are also associated with pronounced and persistent Arctic cooling (Fig. 1f) in the lower stratosphere, which is in contrast to the significant warming that starts about 1 week before VI onset in the upper stratosphere. The warming slowly propagates downward, persists until spring, and finally becomes part of the FW that con- 
cludes the winter season. The timing and strength of the FW is another important difference between SSWs and VIs. While FWs after SSWs tend to be late and mostly represent a transition into climatology, FWs after VIs occur early, are relatively strong, and contribute to a pronounced weakening and warming of the vortex.

\subsection{Arctic ozone changes}

The above-described dynamical perturbations are associated with significant changes in the transport of stratospheric ozone and its temperature-dependent photochemical reaction rates. As has been shown to some extent before (Butler et al., 2017; de la Cámara et al., 2018b; Hocke et al., 2015), and as we will show in more detail next, this has major consequences for the distribution of stratospheric ozone.

We first examine the composite evolution of Arctic column ozone (i.e., the vertically integrated ozone amount) during SSWs (Fig. 2a). Red and gray shading indicate the deviation of the column ozone from its climatology (thick black curve), and the green line shows the percent column ozone anomaly with respect to climatology. Before onset, there is a subtle decrease in column ozone, presumably related to the anomalously strong and cold vortex during this time (Fig. 1e) and the reduced ozone transport into the polar regions. Within the first $10 \mathrm{~d}$ following the SSW onset, the column ozone anomalies rapidly increase by $\sim 50 \mathrm{DU}$ and persist for up to $60 \mathrm{~d}$ until late winter. Hocke et al. (2015) suggested that the increases in column ozone after SSWs amount to up to $90 \mathrm{DU}$ over the Arctic, which is nearly twice that of what we found. However, we note that the differences are only apparent as we show area-weighted latitudinal averages of column ozone and as the extreme ozone increases, in Hocke et al. (2015), occur only close to the pole. The vertically resolved Arctic ozone mixing ratio (Fig. 2c) shows a more complicated picture. There is a pronounced reduction in ozone in the middle and upper stratosphere after SSWs, which seems to be slowly descending downward. This decrease in midstratospheric ozone, which starts about 1 month after SSWs, has also been noted by Sagi et al. (2017). Ozone in the upper stratosphere also undergoes a complicated evolution. The negative anomalies above $5 \mathrm{hPa}$ exist only shortly during the onset. They are followed by persistent positive anomalies, which again tend to descend downward by mid-March, diminish by April, and reemerge at midstratospheric levels by the end of April as a consequence of the FW.

Next, we examine the evolution of Arctic ozone during VIs (Fig. 2b, d, f). Column ozone (Fig. 2b) is anomalously negative over the entire VI life cycle, minimizing at about -40 DU by mid-March. Figure $2 \mathrm{~d}$ demonstrates that the negative ozone anomalies maximize in the middle stratosphere at $\sim 10 \mathrm{~d}$ after onset and also tend to propagate downward into the lower stratosphere. These anomalies are particularly long lasting in the lower stratosphere, where they exist for more than $60 \mathrm{~d}$ until the FW. This composite behavior is very similar to the case study by Manney and Lawrence (2016), who reported that the rapid Arctic chemical ozone loss during winter 2015-2016 was abruptly terminated by the early FW in March. Ozone anomalies are also negative in the upper stratosphere, where they persist throughout the VI life cycle and tend to descend after the FW. At the FW, there are strongly positive ozone anomalies in the middle stratosphere. The structure of these anomalies is somewhat similar to that of SSWs, except that they are weakly negative in the lowermost stratosphere.

We now explore the role of the dynamical mechanisms that create the changes in ozone. From the TEM tracer transport equation Eq. (1), it is clear that several processes are involved. Figure $2 \mathrm{e}-\mathrm{j}$ present the total time tendencies of ozone (Fig. 2e-f) and the contributions to it from vertical advection (Fig. 2g-h) and eddy flux convergence (Fig. 2i-j). The horizontal advection term is generally small and therefore omitted. For better orientation, the red and blue contours reproduce a constant ozone mixing ratio anomaly from Fig. $2 \mathrm{c}$ and d.

The negative Arctic ozone anomalies in early winter, before SSWs, are partly the result of reduced eddy flux convergences (Fig. 2i) and vertical transport (Fig. 2g). The strong positive ozone tendencies close to the onset of SSWs, which are responsible for the increase in ozone after SSWs, result mainly from the convergence of eddy fluxes (Fig. 2i; see also de la Cámara et al., 2018b), triggered by the enhanced wave driving associated with SSWs (Fig. 1a). The downward transport of ozone by the enhanced residual circulation also contributes to the positive tendencies during onset, in particular in the lower stratosphere (Fig. 2g). After SSWs, the suppressed planetary wave activity leads to a sustained reduction in eddy transport and, hence, negative ozone tendencies in the middle and lower stratosphere. At the same time, the vertical advection of ozone is anomalously negative in the middle stratosphere after SSWs. Both effects lead to the gradual decay of the strongly positive ozone anomalies right after onset and eventually create the abovementioned banded structure of negative ozone in the middle stratosphere. Overall, this indicates that the decrease in midstratospheric ozone after SSWs is mainly of dynamical origin, consistent with de la Cámara et al. (2018b). We note that this does not support the ideas of Sagi et al. (2017), who argue that the ozone decrease is due to chemical reactions involving $\mathrm{NO}_{x}$ species. During the time of the FW, the eddy flux convergence becomes somewhat positive (Fig. 2i), leading, overall, to ozone mixing ratios that are close to climatology. In the upper stratosphere, the temperature-dependent photochemistry plays a dominant role for ozone. There, ozone is mostly anticorrelated with temperature (Craig and Ohring, 1958), which can be seen by comparing Fig. 1e (for temperature) with Fig. 2c (for ozone).

The VI-related total Arctic ozone tendencies (Fig. 2f) are mostly equal but opposite in sign to that of SSWs. VIs are passive events that develop gradually by radiative cooling out to space, and the related negative ozone anomalies ap- 

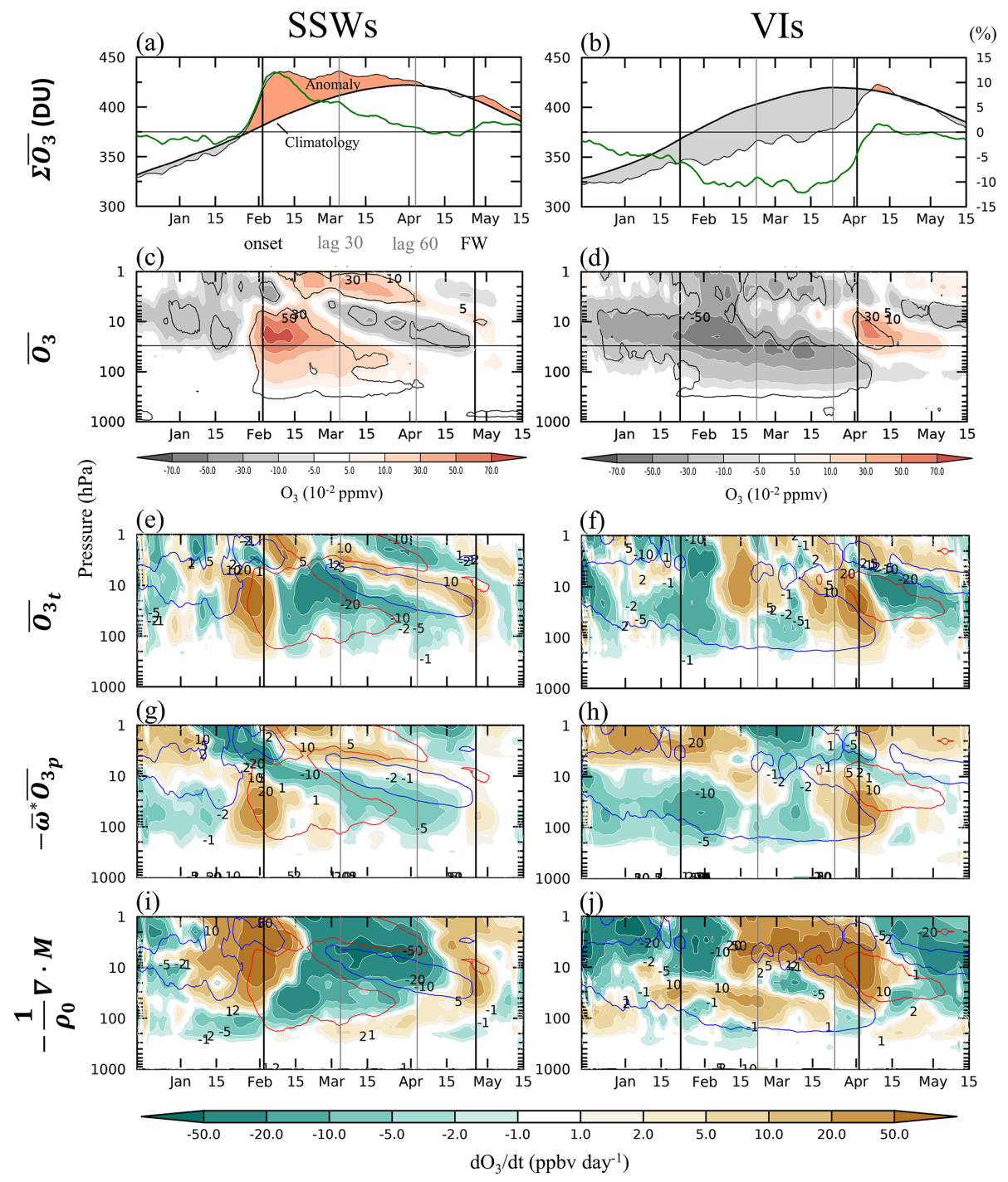

1000 (j)

Figure 2. Arctic ozone composites during (a, c, e, g, i) SSWs and (b, d, f, h, j) VIs. (a-b) Column ozone (left $y$ axis) and associated percent anomalies with respect to climatology (right $y$ axis); the horizontal line is the zero anomaly. The remaining panels are the anomalous time-height cross sections of (c-d) the ozone mixing ratio $\left(10^{-2}\right.$ parts per million by volume - ppmv), (e-f) overall ozone tendency, ozone tendency due to $(\mathbf{g}-\mathbf{h})$ vertical advection and $(\mathbf{i}-\mathbf{j})$ eddy flux convergence (parts per billion by volume - ppbv $^{-1}$ ). Quantities are averaged over $65-90^{\circ} \mathrm{N}$ for ozone and $65-85^{\circ} \mathrm{N}$ for tendencies. Horizontal lines in panels (c)-(d) mark the $30 \mathrm{hPa}$ level, and the contours represent the statistical significance at the $95 \%$ level. Contours in panels (e)-(j) represent the \pm 0.1 ppmv ozone anomalies from panels (c)-(d).

pear long before the actual onset (Fig. 2d), which is related to periods of negative tendencies before and during VI onset (Fig. 2f). The tendencies are related to reduced eddy transport in the upper half (Fig. 2j) and reduced vertical advection in the lower half of the stratosphere (Fig. 2h). Ozone in the upper stratosphere slowly recovers towards climatology, mostly due to increases in eddy transport associated with pulses of planetary waves that restore the vortex back to normal. However, the positive eddy transport is counteracted by the photochemical effect as the temperature is anomalously warm in this layer (Fig. 1f). In contrast, the negative ozone anomalies in the lower stratosphere are sustained by reduced vertical advection (Fig. 2h) until mid-March. We also examined the source term $S$ (not shown) and found negative tendencies in the lower stratosphere $(10-100 \mathrm{hPa})$ during and after the onset of VIs, indicative of temperature-driven heterogeneous ozone depletion, as suggested by previous studies (Isaksen et al., 2012; Manney et al., 2011, 2020). In the upper stratosphere, $S$ is, as expected, mostly anticorrelated with $T$. As explained before, FWs that follow VIs tend to be relatively strong and somewhat resemble SSWs, leading to sizable increases in Arctic ozone. As with SSWs, this is associated with positive eddy transport in the upper half (Fig. $2 \mathrm{j}$ ) and positive vertical advection in the lower half of the strato- 
sphere (Fig. 2h). The two effects compensate for the prior ozone deficits, leading to an overall recovery of the column ozone anomalies (Fig. 2b).

\section{Tropical ozone}

\subsection{Tropical circulation changes}

We now turn our attention to the tropics, defined as the $\pm 15^{\circ}$ latitude band. Tropical ozone is changing in response to Arctic circulation events because of the global nature of the meridional overturning and its role in the transport of ozone (Randel, 1993). We start our discussion by focusing on the changing dynamics in the tropics during Arctic circulation events (Fig. 3). Note that no filtering has been applied to this figure, and that the shown changes can be due to both the remote impacts from the Arctic circulation events and the local effects from the internal variability associated with the QBO. However, the Arctic circulation events occur mostly at random, with respect to the $\mathrm{QBO}$ phase, so that the compositing largely removes possible QBO effects from the shown dynamical fields. This is also supported by the fact that Fig. 3 does not resemble the known influences of the QBO phases on the dynamics (e.g., Coy et al., 2016; their Fig. 8). During SSWs, the variations in $\bar{\omega}^{*}$ (Fig. 3a) are largely opposite to those in the Arctic (Fig. 1c; de la Cámara et al., 2018a), except during the time of the FW. This demonstrates that the global nature of the enhanced residual circulation during SSWs also affects the tropics, leading to stronger upwelling and cooling. The cooling persists in the lower stratosphere, but quickly transitions into warming in the middle and upper stratosphere (Fig. 3c; see also Gómez-Escolar et al., 2014; Tao et al., 2015).

In comparison with the SSWs, the variations in $\bar{\omega}^{*}$ during VI onset (Fig. 3b) are less well synchronized with those in the Arctic (Fig. 1d), perhaps due to the relative weakness of the wave driving and also due to influences from the QBO. Although $\bar{\omega}^{*}$ is quite noisy, temperatures during VI onset show significant warming in the tropical lower stratosphere (Fig. 3d), which is probably related to adiabatic warming from anomalous downwelling (Fig. 3b). By mid-February, a downward-propagating cooling anomaly can be seen in the tropical upper stratosphere (Fig. 3d), as one would expect from the anomalous upwelling (Fig. 3b). As noted before, FWs after VIs are dynamically similar to SSWs, and this is also noticeable in the tropics. For example, the enhanced extratropical wave driving at the $\mathrm{FW}$ is also reflected in the tropical $\bar{\omega}^{*}$.

\subsection{QBO influences on tropical ozone}

Understanding the changes in tropical ozone in response to Arctic stratospheric circulation events is complicated by the simultaneous influences from the QBO. To disentangle the two effects, we first examine how the vertical structure of tropical ozone changes in response to the QBO. Figure 4a shows the vertical cross section of tropical ozone anomalies $\left( \pm 15^{\circ}\right)$ composited on the phase of the QBO from 16 QBO cycles. The black curve represents the mean evolution of UEQ30, where a QBO cycle is defined by two consecutive maxima in UEQ30. Assuming a mean QBO period of 28 months (Baldwin et al., 2001), a $1^{\circ}$ phase change of the QBO corresponds to $\sim 2.3 \mathrm{~d}$. Tweedy et al. (2017) performed a similar analysis (their Fig. 1) by defining the central month of a QBO cycle from changes in the vertical wind shear at $40 \mathrm{hPa}$ and taking QBO composites for different lags. Our results (Fig. 4a) are in good agreement with their study; for example, there is a nodal point of small ozone variations between 10 and $20 \mathrm{hPa}$, with much stronger variations above and below. Our result also agrees with Baldwin et al. (2001) that the maximum column ozone values occur when the westerly wind shear descends into the lowermost stratosphere. The vertical structure of the QBO ozone anomalies in Fig. 4a also shows two maxima at $\sim 10$ and $\sim 30 \mathrm{hPa}$, shifted by about a quarter QBO cycle and consistent with previous findings (Coy et al., 2016; Randel and Wu, 1996).

Figure $4 \mathrm{~b}$ demonstrates that SSWs and VIs occur during virtually any phase of the QBO. However, as shown by the mean timing of the events ( $\mathrm{V}$ and $\mathrm{S}$ markers on the right), there is a slight preference for SSWs to occur during the easterly QBO phase and VIs during the westerly QBO phase, a possibility that was discussed by Dunkerton et al. (1988). To filter out possible QBO influences from the tropical ozone, we define the QBO ozone signal as the mean ozone anomalies over days -60 to -30 with respect to the SSW/VI central date, which is then subtracted from the ozone associated with each Arctic circulation event. We used the resulting ozone anomalies to prepare Fig. $5 \mathrm{c}$ and d.

\subsection{Tropical ozone changes}

Figure 5 presents composite anomalies and composite anomalous tendencies in tropical ozone during SSWs and VIs. The variations in tropical column ozone are rather small and amount to only $\sim 0.5 \%-1 \%$ of the climatological values, which can be compared to the $10 \%-15 \%$ changes seen over the Arctic. Nevertheless, the changes in tropical ozone are quite coherent and persistent. SSWs are followed by a small reduction in tropical column ozone by $\sim 2.5 \mathrm{DU}$ $(\sim-1 \%)$ and an increase by $\sim 1-2 \mathrm{DU}(\sim 0.5 \%)$ after midMarch, which persists until late spring. Figure $5 \mathrm{c}$ shows the vertically resolved composite for tropical ozone after removing the preexisting ozone signal from the QBO, indicating that the local tropical ozone anomalies associated with SSWs are confined to levels above $\sim 60 \mathrm{hPa}$. During SSW onset, the response of ozone is characterized by significant increases in the upper stratosphere and decreases below the middle stratosphere $(\sim 10 \mathrm{hPa})$, roughly opposite to those in the Arctic (Fig. 2c). The ozone anomalies reverse sign after midFebruary and persist into late spring. 

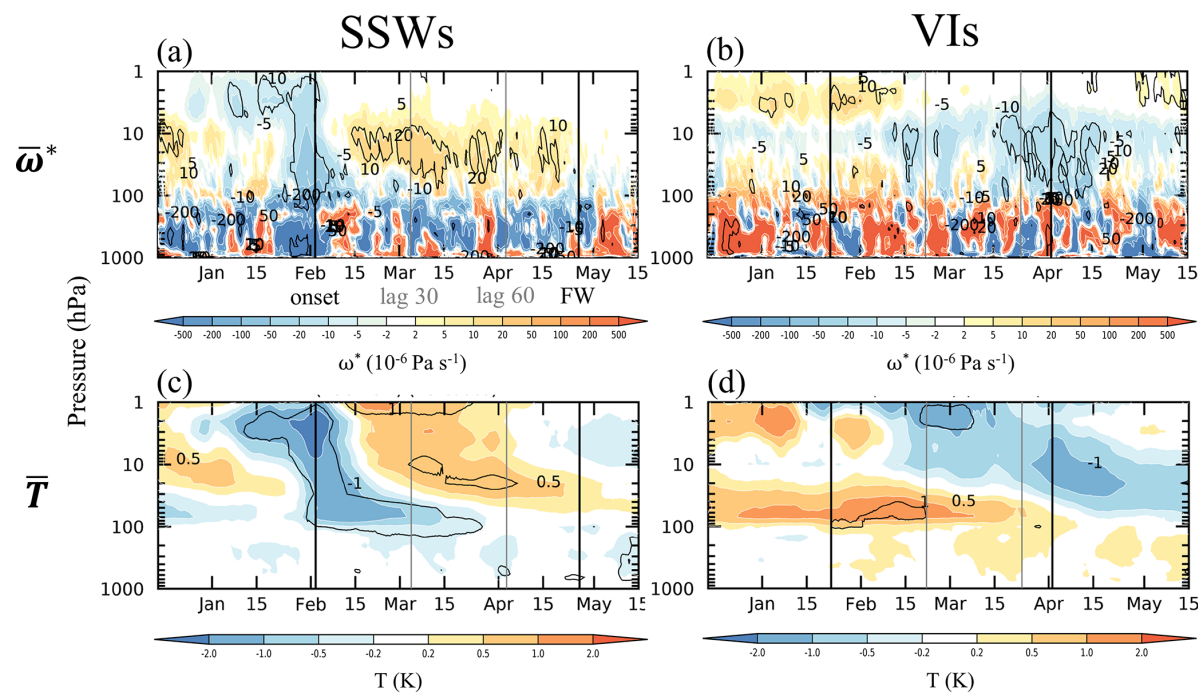

Figure 3. Composite anomalies for $(\mathbf{a}, \mathbf{c})$ SSWs and $(\mathbf{b}, \mathbf{d})$ VIs over the tropical belt $\left( \pm 15^{\circ}\right)$. Shown are time-height cross sections for $(\mathbf{a}-$ b) the vertical component of the residual mean circulation $\left(10^{-6} \mathrm{~Pa} \mathrm{~s}^{-1}\right)$ and (c-d) temperature (K). Contours are as in Fig. 1.
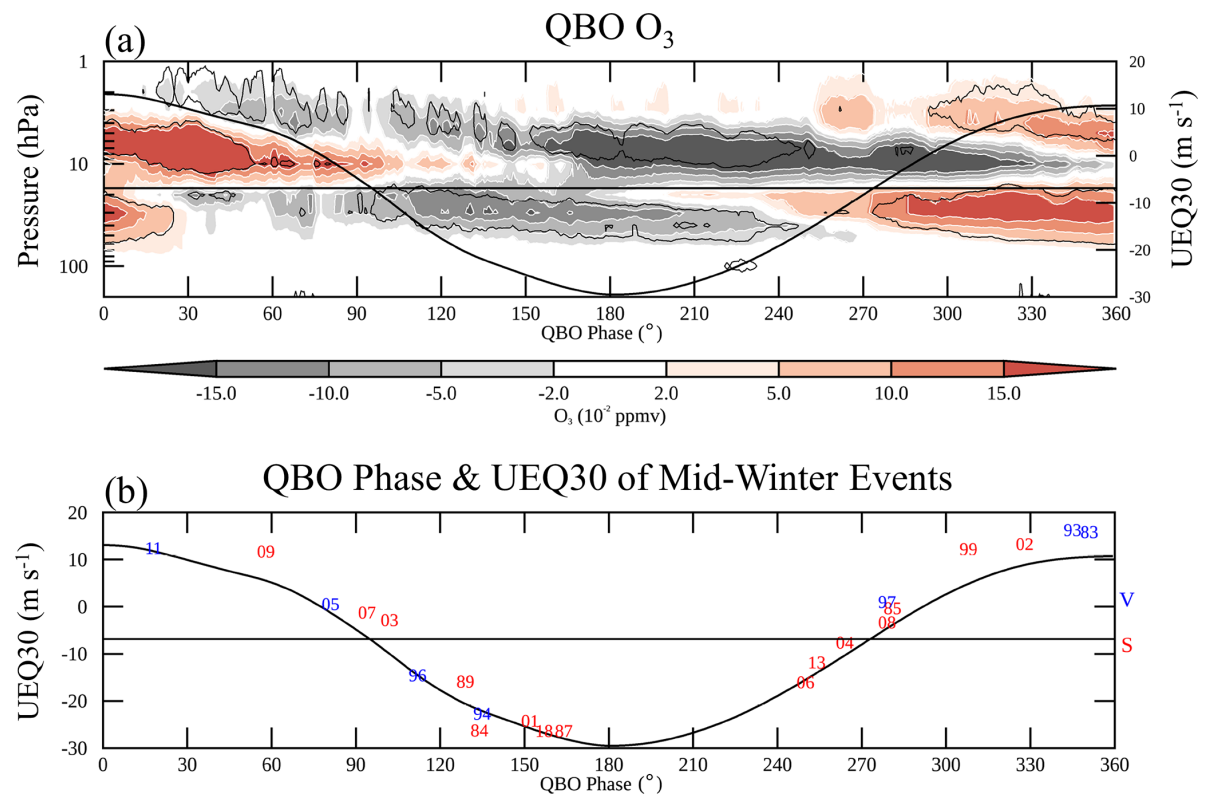

Figure 4. Composites for QBO events. (a) QBO influences on tropical ozone - shading shows composite tropical ozone anomalies $\left( \pm 15^{\circ}\right)$ from 16 QBO cycles (1980-2018), and black contours represent statistical significance at the $95 \%$ level. A QBO cycle is defined by two consecutive positive UEQ30 maxima. (b) Central date timing of selected midwinter stratospheric circulation events relative to the QBO phase. Red (blue) numbers indicate years and QBO phase of SSWs (VIs); S and V on the $y$ axis are the mean UEQ30 of all SSWs and all VIs (except 2016), respectively. The 2015-2016 QBO event has been purposely excluded from this analysis due to the anomalous nature of this event. The horizontal line is the climatological mean UEQ30.

During VIs (Fig. 5b), there are small tropical column ozone anomalies, which are mostly positive $(\sim 1 \mathrm{DU}$ or $0.5 \%)$ and only become negative $(\sim 2 \mathrm{DU}$ or $1 \%)$ after the FW. However, the vertically resolved ozone anomalies with the QBO influence removed (Fig. 5d) show a weak dipole in the middle stratosphere around the onset, with little response in the lower stratosphere. This indicates that the increased column ozone anomalies in Fig. 5b are likely due to the QBO. As discussed before, the weak tropical ozone response to VIs is linked to the relative weakness of the wave driving during VIs, which is not sufficient to affect the tropical upwelling. However, during the FW of VIs, the wave driving anomaly is strong enough; the resulting tropical ozone 

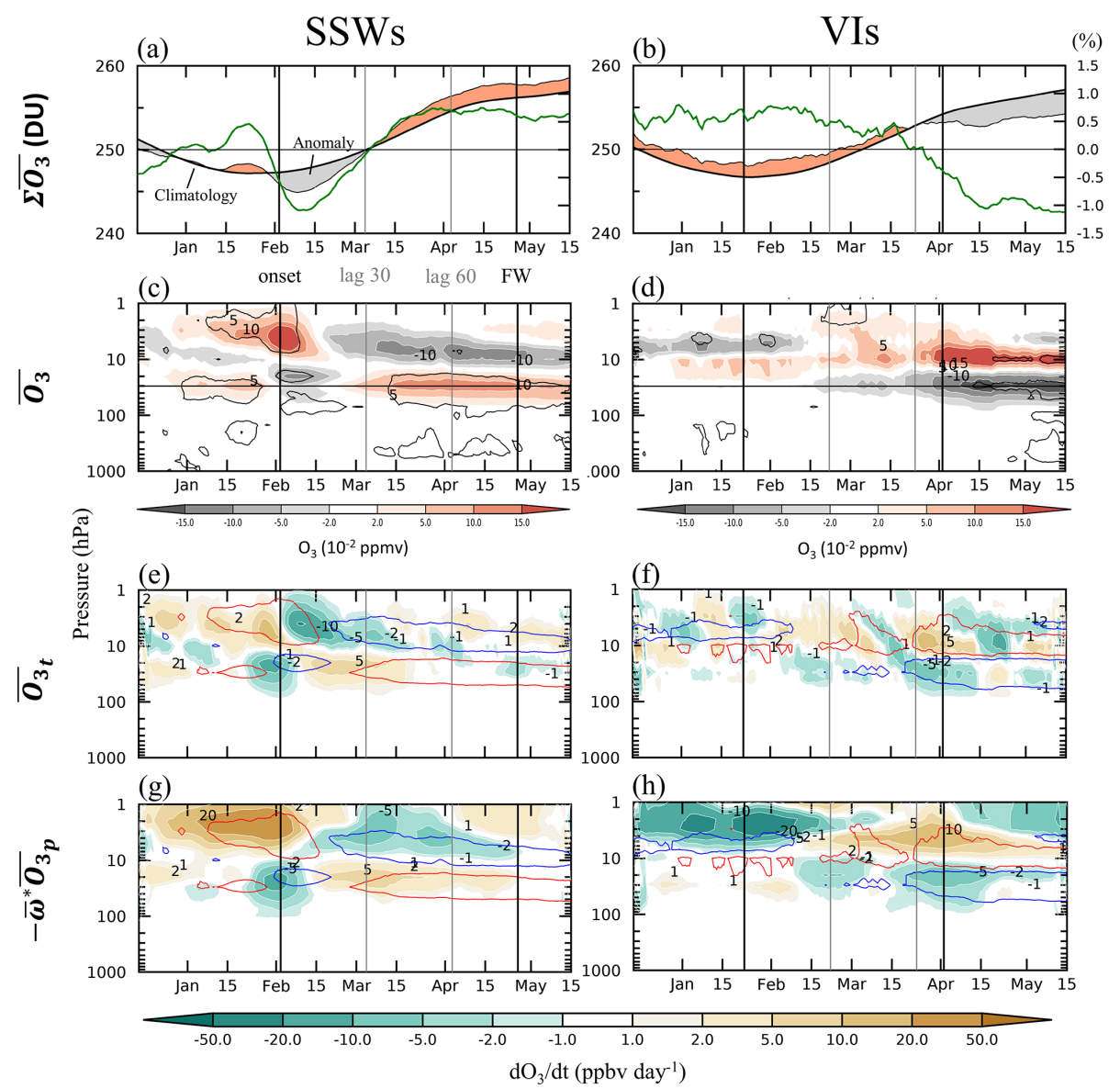

Figure 5. As in Fig. 2, except for tropical ozone $\left( \pm 15^{\circ}\right)$ and the exclusion of the eddy flux convergence term. Contours in panels (e)-(h) are the \pm 0.05 ppmv ozone anomalies from panels (c)-(d).

response is similar to that during SSW onset, with a strong and persistent dipole centered at $\sim 20 \mathrm{hPa}$.

The dynamical mechanisms that create the changes in tropical ozone are dominated by vertical advection associated with changes to the residual circulation (Randel, 1993). Enhanced tropical upwelling during SSW onset (Fig. 3a) combined with a vertical background of ozone mixing ratios that maximize in the middle stratosphere create positive tendencies above $10 \mathrm{hPa}$ and negative tendencies below $10 \mathrm{hPa}$ (Fig. 5g). Following the reversal of the residual circulation anomalies at about $10 \mathrm{~d}$ after onset (Fig. 3a), the vertical advection term leads to oppositely signed ozone anomalies starting at about mid-February. During VIs, the tropical ozone tendencies (Fig. 5f) are mostly small. There are negative tendencies from vertical advection (Fig. $5 \mathrm{~h}$ ) in the upper stratosphere and during onset, owing to the weakened meridional circulation from the VI. However, these negative tendencies are compensated by the chemical source term (not shown), leading, overall, to little change in ozone. As expected, the tropical ozone tendencies during the FW of VIs (Fig. 5f) are mostly due to vertical advection (Fig. 5h) and compensating influences from the source term $\bar{S}$ (not shown).

\section{Summary and conclusion}

We used MERRA-2 reanalysis to document the composite spatiotemporal ozone response to Arctic circulation events. While the ozone response in the Arctic to sudden stratospheric warming (SSW) events has already been the target of some previous studies (Butler et al., 2017; de la Cámara et al., 2018b; Hocke et al., 2015), we took a more holistic approach and studied stratospheric ozone in the Arctic and the tropics, and we considered not only SSWs but also vortex intensification (VI) and final warming (FW) events.

In the Arctic, the onset of SSWs leads to a rapid increase in total ozone by $\sim 50 \mathrm{DU}$, which, over the course of $\sim 60 \mathrm{~d}$, gradually transitions towards climatology before the subsequent FWs. Diagnostic analysis, using the TEM tracer transport equation, indicates that, through the entire life cycle of SSWs, ozone transport by eddies prevails over vertical transport from the anomalous mean meridional circulation. In contrast, during VIs, Arctic ozone exhibits a slow but progressive decrease, which begins in early winter and results in a $\sim 40 \mathrm{DU}$ reduction by mid-March. The strongest negative ozone tendencies take place right after the central date of 
VIs, attributable to weakened vertical transport in the lower stratosphere and decreased eddy transport in the upper stratosphere. VIs conclude the winter with a relatively early and strong FW, resembling a midwinter SSW in terms of the dynamics and ozone perturbations. In contrast, FWs that follow SSWs are relatively late and less remarkable, representing a mostly smooth transition according to climatology. SSWs also have distinct ozone impacts in the tropics. By removing signals attributable to the QBO, we found tropical ozone responses to SSWs that are largely concurrent and inverse to their Arctic counterparts. At SSW onset, tropical ozone decreases below $10 \mathrm{hPa}$ and increases above, with an opposite behavior after $\sim 20 \mathrm{~d}$ when the residual circulation reverses and persists toward the FW. VIs show some obscure tropical ozone responses during onset, presumably due to the relatively weak planetary wave driving anomalies. However, during the FW, VIs are associated with pronounced tropical ozone anomalies due to enhanced vertical transport.

There are also some limitations to this study. In terms of the mechanisms, we were mostly focused on the various dynamical effects in changing ozone. However, chemical effects are likely to also play some role in perturbing ozone, in particular in the chemically dominated upper stratosphere. We were unable to investigate the chemical effects because of the large uncertainties associated with the chemical term in the MERRA-2 reanalysis, but we suspect that the dynamics are, overall, more important than the chemistry. This is supported by Isaksen et al. (2012), who found that the chemical effect explained only $23 \%$ of the Arctic ozone loss during the VI from 2011. Nevertheless, it would be interesting to evaluate the relative contributions from the dynamics and the chemistry in changing ozone during SSWs and VIs, using output from a range of coupled chemistry climate models (CCMs), similar in spirit to de la Cámara (2018b) for SSWs, using the Whole Atmosphere Community Climate Model (WACCM). We also did not explicitly consider so-called downward planetary wave coupling events (DWCs; Lubis et al., 2017), which are relatively short-lived events $(<10 \mathrm{~d})$ associated with increases in ozone before and decreases in ozone during the event, leading to a relatively small net response. Our VI events also need to be distinguished from so-called reflective winters, introduced by Shaw and Perlwitz (2013) and discussed by Lubis et al. (2017), to indicate winters in which wave reflection dominates. Although defined in different ways, there is some overlap between years with VIs and reflective winters, and they are both associated with negative anomalies in wave driving and ozone.

One of the novel results of this study is that FWs that follow VIs induce a surprisingly strong ozone response, which resembles, in many respects, that of midwinter SSWs. Another relatively new aspect of this study is that Arctic circulation events also perturb ozone in the tropics, which is most pronounced during SSWs and early FWs after VIs. This adds to an increasing body of evidence that the mean meridional circulation communicates the effects of Arctic stratospheric circulation events into the lower latitudes. This leads to the notion that the Arctic circulation extremes have an almost global reach, as also evidenced by their impacts on equatorial stratospheric temperatures (Dhaka et al., 2015) and tropospheric equatorial convective activity (Kodera, 2006). It still remains to be seen how the tropical circulation is affected by the combined heating effects from the tropical ozone and the meridional circulation.

Recent studies have suggested that the dynamical coupling between the stratosphere and the troposphere, and the surface impact of this coupling, is simulated more strongly in models with interactive ozone chemistry (i.e., CCMs; Haase and Matthes, 2019; Li et al., 2016; Romanowsky et al., 2019), suggesting that intraseasonal variations in ozone are important for the prediction of short-term climate. The results from our study could serve as a reference for the validation of CCMs. Simulations with CCMs, in turn, could be used to clarify some of the still open questions of the present study, in particular about the response of tropical ozone during VIs and the relative role of photochemistry in changing ozone during the circulation events.

Data availability. MERRA-2 reanalysis data are available online via NASA's Goddard Earth Sciences Data and Information Services Center archive (https://gmao.gsfc.nasa.gov/reanalysis/MERRA-2/ data_access/, Bosilovich et al., 2015).

Author contributions. HJH performed the analysis and wrote the paper. TR designed the study, provided guidance in the interpretation of the results, and reviewed the paper.

Competing interests. The authors declare that they have no conflict of interest.

Acknowledgements. We thank the Department of Atmospheric Sciences at the University of Utah for its support. The use of computer infrastructure from the Center for High Performance Computing at the University of Utah is gratefully acknowledged. We also acknowledge NASA for providing the MERRA-2 reanalysis. Finally, we acknowledge the three anonymous reviewers, Sandro Lubis, and the editor, Peter Haynes, for their constructive comments which helped to improve the paper.

Review statement. This paper was edited by Peter Haynes and reviewed by three anonymous referees. 


\section{References}

Andrews, D. G., Holton, J. R., and Leovoy, C. B.: Middle Atmosphere Dynamics, Orlando, Fla, Academic Press, 1987.

Baldwin, M. P., Gray, L. J., Dunkerton, T. J., Hamilton, K., Haynes, P. H., Randel, W. J., Holton, J. R., Alexander, M. J., Hirota, I., Horinouchi, T., Jones, D. B. A., Kinnersley, J. S., Marquardt, C., Sato, K., and Takahashi, M.: The quasi-biennial oscillation, Rev. Geophys., 39, 179-229, https://doi.org/10.1029/1999RG000073, 2001.

Black, R. X. and McDaniel, B. A.: The dynamics of Northern Hemisphere stratospheric final warming events, J. Atmos. Sci., 64, 2932-2946, https://doi.org/10.1175/JAS3981.1, 2007.

Bosilovich, M. G., Akella, S., Coy, L., Cullather, R., Draper, C., Gelaro, R., Kovach, R., Liu, Q., Molod, A., Norris, P., Wargan, K., Chao, W., Reichle, R., Takacs, L., Vikhliaev, Y., Bloom, S., Collow, A., Firth, S., Labows, G., Partyka, G., Pawson, S., Reale, O., Schubert, S. D., and Suarez, M.: MERRA-2: Initial Evaluation of the Climate, Technical Report Series on Global Modeling and Data Assimilation, Tech. Rep. NASA/TM2015-104606, availabe at: http://gmao.gsfc.nasa.gov/reanalysis/ MERRA-2/docs/ (last access: 13 January 2020), 2015.

Butler, A. H., Sjoberg, J. P., Seidel, D. J., and Rosenlof, K. H.: A sudden stratospheric warming compendium, Earth Syst. Sci. Data, 9, 63-76, https://doi.org/10.5194/essd-9-63-2017, 2017.

Charlton, A. J. and Polvani, L. M.: A new look at stratospheric sudden warmings. Part I: Climatology and modeling benchmarks, J. Climate, 20, 449-469, https://doi.org/10.1175/JCLI3996.1, 2007.

Coy, L., Wargan, K., Molod, A. M., McCarty, W. R., and Pawson, S.: Structure and dynamics of the quasibiennial oscillation in MERRA-2, J. Climate, 29, 5339-5354, https://doi.org/10.1175/JCLI-D-15-0809.1, 2016.

Craig, R. A. and Ohring, G.: The temperature dependence of ozone radiational heating rates in the vicinity of the mesopeak, J. Meteor., 15, 59-62, 1958.

Davis, S. M., Hegglin, M. I., Fujiwara, M., Dragani, R., Harada, Y., Kobayashi, C., Long, C., Manney, G. L., Nash, E. R., Potter, G. L., Tegtmeier, S., Wang, T., Wargan, K., and Wright, J. S.: Assessment of upper tropospheric and stratospheric water vapor and ozone in reanalyses as part of S-RIP, Atmos. Chem. Phys., 17, 12743-12778, https://doi.org/10.5194/acp-17-127432017, 2017.

de la Cámara, A., Abalos, M., and Hitchcock, P.: Changes in stratospheric transport and mixing during sudden stratospheric warmings, J. Geophys. Res.-Atmos., 123, 3356-3373, https://doi.org/10.1002/2017JD028007, 2018a.

de la Cámara, A., Abalos, M., Hitchcock, P., Calvo, N., and Garcia, R. R.: Response of Arctic ozone to sudden stratospheric warmings, Atmos. Chem. Phys., 18, 16499-16513, https://doi.org/10.5194/acp-18-16499-2018, 2018 b.

Dhaka, S. K., Kumar, V., Choudhary, R. K., Ho, S.P., Takahashi, M., and Yoden, S.: Indications of a strong dynamical coupling between the polar and tropical regions during the sudden stratospheric warming event January 2009, based on COSMIC/FORMASAT3 satellite temperature data, Atmos. Res., 166, 60-69, https://doi.org/10.1016/j.atmosres.2015.06.008, 2015.

Dunkerton, T. J., Delisi, D. P., and Baldwin, M. P.: Distribution of major stratospheric warmings in relation to the quasi-biennial oscillation, Geophys. Res. Lett., 15, 136-139, https://doi.org/10.1029/GL015i002p00136, 1988.

Eliassen, A. and Palm, E.: On the transfer of energy in stationary mountain waves, Geofys. Publ., 22, 1-23, 1961.

Gómez-Escolar, M., Calvo, N., Barriopedro, D., and Fueglistaler, S.: Tropical response to stratospheric sudden warmings and its modulation by the QBO, J. Geophys. Res.-Atmos., 119, 73827395, https://doi.org/10.1002/2013JD020560, 2014.

Haase, S. and Matthes, K.: The importance of interactive chemistry for stratosphere-troposphere coupling, Atmos. Chem. Phys., 19, 3417-3432, https://doi.org/10.5194/acp-19-3417-2019, 2019.

Hartmann, D. L., Wallace, J. M., Limpasuvan, V., Thompson, D. W. J., and Holton, J. R.: Can ozone depletion and global warming interact to produce rapid climate change, P. Natl. Acad. Sci. USA, 97, 1412-1417, https://doi.org/10.1073/pnas.97.4.1412, 2000.

Hitchcock, P. and Shepherd, T. G.: Zonal-mean dynamics of extended recoveries from stratospheric sudden warmings, J. Atmos. Sci., 70, 688-707, https://doi.org/10.1175/JAS-D-120111.1, 2013.

Hocke, K., Lainer, M., and Schanz, A.: Composite analysis of a major sudden stratospheric warming, Ann. Geophys., 33, 783788, https://doi.org/10.5194/angeo-33-783-2015, 2015.

Horan, M. F. and Reichler, T.: Modeling seasonal sudden stratospheric warming climatology based on polar vortex statistics, J. Climate, 30, 10101-10116, https://doi.org/10.1175/JCLI-D-170257.1, 2017.

$\mathrm{Hu}$, J., Ren, R., and Xu, H.: Occurrence of winter stratospheric sudden warming events and the seasonal timing of spring stratospheric final warming, J. Atmos. Sci., 71, 2319-2334, https://doi.org/10.1175/JAS-D-13-0349.1, 2014.

Isaksen, I. S. A., Zerefos, C., Wang, W.-C., Balis, D., Eleftheratos, K., Rognerud, B., Stordal, F., Berntsen, T. K., LaCasce, J. H., Søvde, O. A., Olivié, D., Orsolini, Y. J., Zyrichidou, I., Prather, M., and Tuinder, O. N. E.: Attribution of the Arctic ozone column deficit in March 2011, Geophys. Res. Lett., 39, L24810, https://doi.org/10.1029/2012GL053876, 2012.

Kodera, K.: Influence of stratospheric sudden warming on the equatorial troposphere, Geophys. Res. Lett., 33, L06804, https://doi.org/10.1029/2005GL024510, 2006.

Kuroda, Y. and Kodera, K.: Variability of the polarnight jet in the Northern and Southern Hemispheres, J. Geophys. Res., 106, 20703-20713, https://doi.org/10.1029/2001JD900226, 2001.

Leovy, C. B., Sun, C.-R., Hitchman, M. H., Remsberg, E. E., Russell, J. M., Gordley, L. L., Gille, J. C., and Lyjak, L. V.: Transport of ozone in the middle stratosphere: Evidence for planetary wave breaking, J. Atmos. Sci., 42, 230-244, https://doi.org/10.1175/15200469(1985)042<0230:TOOITM>2.0.CO;2, 1985.

Li, F., Vikhliaev, Y. V., Newman, P. A., Pawson, S., Perlwitz, J., Waugh, D. W., and Douglass, A. R.: Impacts of interactive stratospheric chemistry on Antarctic and Southern Ocean climate change in the Goddard Earth Observing System, version 5 (GEOS-5), J. Climate, 29, 3199-3218, https://doi.org/10.1175/JCLI-D-15-0572.1, 2016.

Limpasuvan, V., Thompson, D. W. J., and Hartmann, D. L.: The life cycle of the Northern Hemisphere sudden stratospheric warm- 
ings, J. Climate, 17, 2584-2596, https://doi.org/10.1175/15200442(2004)017<2584:TLCOTN>2.0.CO;2, 2004.

Limpasuvan, V., Hartmann, D. L., Thompson, D. W. J., Jeev, K., and Yung, Y. L.: Stratosphere-troposphere evolution during polar vortex intensification, J. Geophys. Res., 110, D24101, https://doi.org/10.1029/2005JD006302, 2005.

Lubis, S. W., Silverman, V., Matthes, K., Harnik, N., Omrani, N.-E., and Wahl, S.: How does downward planetary wave coupling affect polar stratospheric ozone in the Arctic winter stratosphere?, Atmos. Chem. Phys., 17, 2437-2458, https://doi.org/10.5194/acp-17-2437-2017, 2017.

Ma, J., Waugh, D. W., Douglass, A. R., Kawa, S. R., Newman, P. A., Pawson, S., Stolarski, R., and Lin, S. J.: Interannual variability of stratospheric trace gases: The role of extratropical wave driving, Q. J. Roy. Meteor. Soc., 130, 2459-2474, https://doi.org/10.1256/qj.04.28, 2004.

Manney, G. L. and Lawrence, Z. D.: The major stratospheric final warming in 2016: dispersal of vortex air and termination of Arctic chemical ozone loss, Atmos. Chem. Phys., 16, 15371-15396, https://doi.org/10.5194/acp-16-15371-2016, 2016.

Manney, G. L., Santee, M. L., Rex, M., Livesey, N. J., Pitts, M. C., Veefkind, P., Nash, E. R., Wohltmann, I., Lehmann, R., Froidevaux, L., Poole, L. R., Schoeberl, M. R., Haffner, D. P., Davies, J., Dorokhov, V., Gernandt, H., Johnson, B., Kivi, R., Kyrö, E., Larsen, N., Levelt, P. F., Makshtas, A., McElroy, C. T., Nakajima, H., Parrondo, M. C., Tarasick, D. W., Gathen, P., Walker, K. A., and Zinoviev, N. S.: Unprecedented Arctic ozone loss in 2011, Nature, 478, 469-475, https://doi.org/10.1038/nature10556, 2011.

Manney, G. L., Livesey, N. J., Santee, M. L., Froidevaux, L., Lambert, A., Lawrence, Z. D., Millán, L. F., Neu, J. L., Read, W. G., Schwartz, M. J., and Fuller, R. A.: Recordlow Arctic stratospheric ozone in 2020: MLS observations of chemical processes and comparisons with previous extreme winters, Geophys. Res. Lett., 47, e2020GL089063, https://doi.org/10.1029/2020GL089063, 2020.

McIntyre, M. E.: How well do we understand the dynamics of stratospheric warmings, J. Meteorol. Soc. Jpn., 60, 37-65, https://doi.org/10.2151/jmsj1965.60.1_37, 1982.

Newman, P. A., Coy, L., Pawson, S., and Lait, L. R.: The anomalous change in the QBO in 2015-2016, Geophys. Res. Lett., 43, 8791-8797, https://doi.org/10.1002/2016GL070373, 2016.

Plumb, R. A. and Eluszkiewicz, J.: The Brewer-Dobson circulation: Dynamics of the tropical upwelling, J. Atmos. Sci., 56, 868-890, https://doi.org/10.1175/15200469(1999)056<0868:TBDCDO>2.0.CO;2, 1999.

Polvani, L. M. and Waugh, D. W.: Upward wave activity flux as a precursor to extreme stratospheric events and subsequent anomalous surface weather regimes, J. Climate, 17, 3548-3554, https://doi.org/10.1175/15200442(2004)017<3548:UWAFAA>2.0.CO;2, 2004.
Randel, W. J.: Global variations of zonal mean ozone during stratospheric warming events, J. Atmos. Sci., 50, 3308-3321, https://doi.org/10.1175/15200469(1993)050<3308:GVOZMO>2.0.CO;2, 1993.

Randel, W. J. and Wu, F.: Isolation of the ozone QBO in SAGE II data by singular-value decomposition, J. Atmos. Sci., 53, 2546-2559, https://doi.org/10.1175/15200469(1996)053<2546:IOTOQI>2.0.CO;2, 1996.

Randel, W. J., Wu, F., and Stolarski, R.: Changes in column ozone correlated with the stratospheric EP flux, J. Meteorol. Soc. Jpn., 80, 849-862, https://doi.org/10.2151/jmsj.80.849, 2002.

Rienecker, M. M., Suarez, M. J., Todling, R., Bacmeister, J., Takacs, L., Liu, H.-C., Gu, W., Sienkiewicz, M., Koster, R. D., Gelaro, R., Stajner, I., and Nielsen, J. E.: The GEOS-5 Data Assimilation System - Documentation of versions 5.0.1 and 5.1.0, and 5.2.0, NASA Tech. Rep. Series on Global Modeling and Data Assimilation, NASA/TM-2008-104606, Vol. 27, 101 pp., 2008.

Romanowsky, E., Handorf, D., Jaiser, R., Wohltmann, I., Dorn, W., Ukita, J., Cohen, J., Dethloff, K., and Rex, M.: The role of stratospheric ozone for Arctic-midlatitude linkages, Sci. Rep., 9, 7962, https://doi.org/10.1038/s41598-019-43823-1, 2019.

Sagi, K., Pérot, K., Murtagh, D., and Orsolini, Y.: Two mechanisms of stratospheric ozone loss in the Northern Hemisphere, studied using data assimilation of Odin/SMR atmospheric observations, Atmos. Chem. Phys., 17, 1791-1803, https://doi.org/10.5194/acp-17-1791-2017, 2017.

Scherhag, R.: Die explosionsartigen Stratosphärenerwärmungen des Spätwinter 1951-1952, Ber. Dtsch. Wetterd., 6, 51-63, 1952.

Shaw, T. A. and Perlwitz, J.: The life cycle of Northern Hemisphere downward wave coupling between the stratosphere and troposphere, J. Climate, 26, 1745-1763, https://doi.org/10.1175/JCLID-12-00251.1, 2013.

Tao, M., Konopka, P., Ploeger, F., Riese, M., Müller, R., and Volk, C. M.: Impact of stratospheric major warmings and the quasi-biennial oscillation on the variability of stratospheric water vapor, Geophys. Res. Lett., 42, 4599-4607, https://doi.org/10.1002/2015GL064443, 2015.

Tweedy, O. V., Kramarova, N. A., Strahan, S. E., Newman, P. A., Coy, L., Randel, W. J., Park, M., Waugh, D. W., and Frith, S. M.: Response of trace gases to the disrupted 2015-2016 quasi-biennial oscillation, Atmos. Chem. Phys., 17, 6813-6823, https://doi.org/10.5194/acp-17-6813-2017, 2017.

Wargan, K. G., Labow, G., Frith, S., Pawson, S., Livesey, N., and Partyka, G.: Evaluation of the ozone fields in NASA's MERRA-2 reanalysis, J. Climate, 30, 2961-2988, https://doi.org/10.1175/JCLI-D-16-0699.1, 2017. 